\title{
Cell growth and p53 expression in primary acquired melanosis and conjunctival melanoma
}

\author{
S Seregard
}

\begin{abstract}
Aims-To evaluate cell growth and the pattern of p53 suppressor gene expression in atypical primary acquired melanosis (PAM) and in recurrent conjunctival melanoma.
\end{abstract}

Methods-Eighteen specimens of PAM with atypia and 24 specimens, comprising early and late lesions, from 12 patients with conjunctival melanoma were stained for the proliferating cell nuclear antigen using the PC10 antibody, and for the p53 gene product using the BP53-12-1, 1801 and 007 clones. The immunoreactive cells were counted manually and the data evaluated statistically.

Results-Seven of nine PAM specimens progressing to melanoma expressed PC10. None of these lesions expressed the p53 gene product. The number of proliferating cells was higher in the late than in the early lesions of conjunctival melanoma. Four of the 12 recurrent melanomas displayed focal, but minimal, p53 expression. The proliferating cell count in the p53 positive tumours was very similar to that of the p53 negative conjunctival melanomas. Conclusion-Examination of the expression of proliferating cells in atypical PAM may be used as an adjunct to predict which lesions will progress to melanoma. The increase in the number of proliferating cells over time in recurrent conjunctival melanomas probably reflects more aggressive behaviour and may be used to monitor recurrence. The absence of p53 expression in PAM and minimal staining of conjunctival melanomas did not correlate with cell growth, suggesting that alterations in the p53 tumour suppressor gene are uncommon and late events in conjunctival melanoma, and that p53 expression is unlikely to be a useful prognostic indicator.

(f Clin Pathol 1996;49:338-342)

Keywords: p53 expression, recurrent conjunctival melanoma, primary acquired melanosis, malignant transformation, cell proliferation.

Conjunctival malignant melanoma is a rare tumour, with a 10 year, tumour related mortality rate of $30 \% .{ }^{1}$ Some $60 \%$ of patients with conjunctival melanoma experience recurrences, ${ }^{12} 32 \%$ have more than one recurrence ${ }^{2}$ and many patients with multiple recurrences finally undergo orbital exenteration due to unresectable tumours. ${ }^{3}$ This suggests that recurrent conjunctival melanomas become more aggressive over time. Primary acquired mel- anosis (PAM) of the conjunctiva is a potential precursor lesion of conjunctival melanoma, and $50 \%$ of lesions with cytological atypia will ultimately progress to malignant melanoma. ${ }^{4}$ While the presence of epitheloid cells and histological patterns other than basal hyperplasia may be more common in atypical PAM giving rise to melanoma, little is known of other predictors of malignant transformation. ${ }^{4}$ It is conceivable that cell proliferation is more marked in atypical PAM that progresses to melanoma than in lesions that remain confined to the epithelium. In addition, if the aggressive behaviour of recurrent conjunctival melanoma correlates with increased cell growth, recurrent disease may be monitored by assessing cell proliferation.

The proliferative compartment may be assessed by the fraction of cells expressing the proliferating cell nuclear antigen (PCNA), a $36 \mathrm{kD}$ nuclear protein associated with the $S$ phase of the cell cycle. ${ }^{5}$ Previous studies indicate that the PC10 monoclonal antibody directed against PCNA may be used to assess prognosis in conjunctival melanoma ${ }^{6}$ The p53 tumour suppressor gene encodes a $53 \mathrm{kD}$ nuclear phosphoprotein believed to be involved in the regulation of cell growth. ${ }^{7}$ p53 gene mutations were first reported in colorectal carcinoma, ${ }^{8}$ and have since been demonstrated in a variety of neoplasms. ${ }^{9}$ Wild-type p53 has a short half-life, five to 20 minutes, and is usually not detectable by immunohistochemical methods. ${ }^{7}$ In contrast, mutant p53 is much more stable and can be detected immunohistochemically. ${ }^{1011}$ The development of antigen retrieval techniques ${ }^{12-14}$ and antibodies that recognise epitopes resistant to denaturation enables the BP53-12-1, ${ }^{15} 1801,{ }^{1617}$ and $\mathrm{DO} 7^{1819}$ clones to be used on formalin fixed, paraffin wax embedded specimens.

\section{Methods}

\section{IMMUNOPATHOLOGY}

A pilot study on the effect of prolonged fixation of tissue in $4 \%$ formaldehyde was undertaken initially. Briefly, tissue samples of a colorectal carcinoma were fixed in $4 \%$ formaldehyde for one, two, seven, and 14 days. These samples were then stained immunohistochemically using the protocol and antibodies outlined below. Positive p53 staining was detected after seven but not 14 days following pretreatment in a microwave oven and with all three p53 antibodies listed below. The BP53-12-1 antibody provided a more intense staining pattern, but all three clones produced satisfactory results. When pretreatment in a microwave oven was omitted, staining with PC10 produced 
Table 1 Clinical data

\begin{tabular}{|c|c|c|c|c|c|c|c|}
\hline Patient & Sex & $A g e^{*}$ & Follow Up† & Recurrences & Exenteration & Metastases & Died of disease \\
\hline 1 & Female & 39 & 68 & 3 & No & Yes & Yes \\
\hline 2 & Female & 67 & 157 & 2 & No & No & No \\
\hline 3 & Female & 41 & 79 & 7 & Yes & Yes & No \\
\hline 4 & Male & 67 & 75 & 4 & Yes & No & No \\
\hline 5 & Male & 66 & 159 & 6 & Yes & No & No \\
\hline 6 & Male & 54 & 68 & 6 & Yes & No & No \\
\hline 7 & Male & 75 & 65 & 3 & Yes & No & No \\
\hline 8 & Male & 47 & 135 & 7 & Yes & No & No \\
\hline 9 & Male & 64 & 163 & 2 & Yes & No & No \\
\hline 10 & Female & 70 & 84 & 2 & No & No & No \\
\hline 11 & Male & 63 & 77 & 3 & Yes & Yes & Yes \\
\hline 12 & Male & 43 & 43 & 2 & Yes & No & No \\
\hline
\end{tabular}

* Age at diagnosis of first lesion; † Follow up (months) after diagnosis of first lesion until end of study or death from any cause.

a positive result after 14 days' fixation. The staining intensity was further improved on microwave pretreatment, even for those specimens fixed in formaldehyde for 14 days.

Eighteen archival specimens of atypical PAM, including nine cases which progressed to melanoma, and 24 specimens, comprising early and late lesions, from 12 patients with recurrent conjunctival melanoma were retrieved from the files of the St Erik's Eye Hospital, Stockholm. Pertinent clinical data were obtained from the hospital records and from the Swedish National Causes of Death Registry (table 1).

Sections, $3 \mu \mathrm{m}$ thick, were cut from each paraffin wax block, deparaffinised and rehydrated. Endogenous peroxidase was blocked by immersing the slides in $3 \% \mathrm{H}_{2} \mathrm{O}_{2}$ for 30 minutes. The tissue slides were then covered with $0.01 \mathrm{M}$ citrate buffer, $\mathrm{pH} 6.0$, and were heated in a microwave oven (Miele M 720, operating at $2450 \mathrm{MHz}$ (Miele, Gütersloh, Germany)) at $780 \mathrm{~W}$ for 10 minutes, with a short pause after the first five. Four slides from each specimen were then incubated overnight with, respectively, PC10 (Dako, Glostrup, Denmark), diluted 1 in 20, DO7 (Dako), diluted 1 in 25, BP53-12-1 (Biogenex, San Ramon, California, USA), diluted 1 in 80 , and 1801 (Biogenex), diluted 1 in 40. The slides were then exposed to avidin-biotin complexes for 60 minutes, stained with 3-amino-9-ethyl-

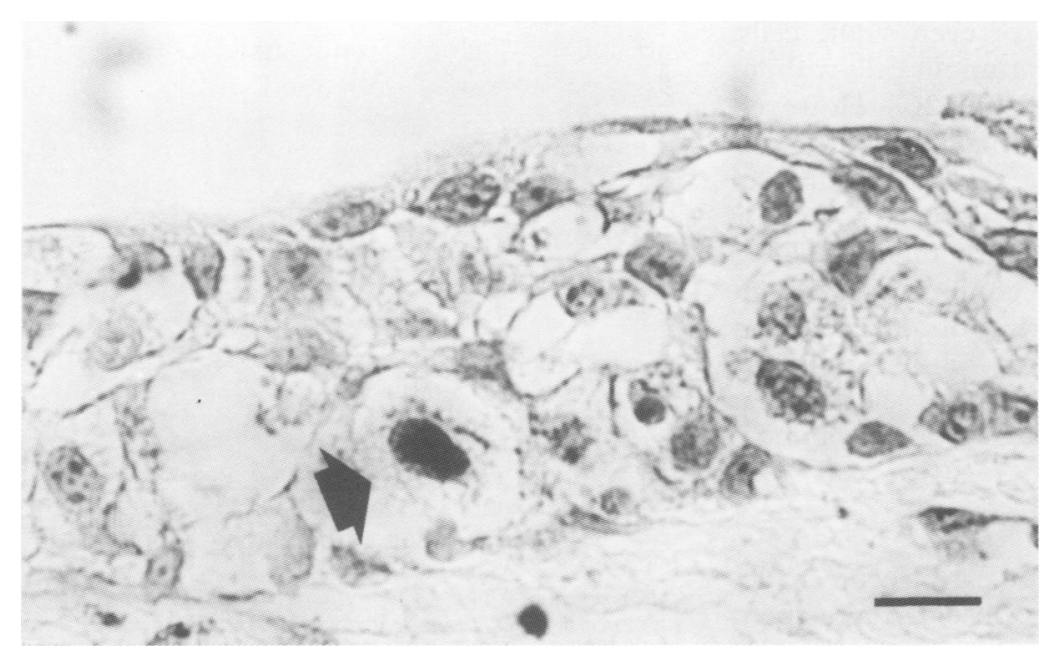

Figure 1 Atypical PAM that subsequently progressed to melanoma (patient 3). A single intraepithelial melanocyte displays strong intranuclear staining for PCNA (arrow). The section was counterstained with Mayer's haematoxylin. Original magnification $\times 910$. $B a r=20 \mathrm{~mm}$. carbazole and counterstained with Mayer's haematoxylin.

Positive controls for all primary antibodies were obtained from paraffin wax blocks of a colorectal carcinoma with previously recorded expression of the $\mathrm{p} 53$ protein in approximately $60-70 \%$ of all tumour cells and a PC10 labelling index of about $40-50 \%$. Negative controls were provided by omitting the primary antibodies from the protocol.

\section{ASSESMENT OF IMMUNOSTAINING}

Eight high power fields $\left(0.0625 \mathrm{~mm}^{2}\right)$ from areas of maximum immunoreactivity were assessed using a Zeiss (Carl Zeiss, Oberkochen, Germany) Axioskop microscope with a $10^{2}$ eyepiece graticule. All cells containing distinct nuclear immunoreactivity were regarded as positive irrespective of the staining intensity. To estimate intra-observer reproducibility, all PC10 counts for the early lesions were repeated blindly. As the BP53-12-1 clone provided the most distinct staining pattern of the antibodies recognising $\mathrm{p} 53$, this clone was used for the quantitative assessment of p53 immunoreactivity.

\section{DATA ANALYSIS}

Data were analysed using following software: CSS:STATISTICA (StatSoft, Tulsa, Oklahoma, USA), Statgraphics 5.0 (STSC, Rockville, Maryland, USA), and Confidence Interval Analysis 1.1 (BMJ, London, UK). Normality was assessed by frequency histograms, and two tailed $t$ tests for paired and unpaired data were then used as appropriate. Non-normal continuous data were analysed by the MannWhitney U test; Fisher's exact test was used for proportions. Statistical significance was set at the $5 \%$ level and hypothesis testing was supplemented by the calculation of $95 \%$ confidence intervals (CI).

\section{Results}

Nine of the 18 patients with atypical PAM eventually developed conjunctival melanoma. The median follow up was 46 months (range 21-233 months) for those patients who did not develop melanoma and was 36 months (range 7-125 months) for those who underwent malignant transformation. This difference was not significant $(p=0 \cdot 12)$. All patients were treated with a combination of surgery and cryotherapy, 

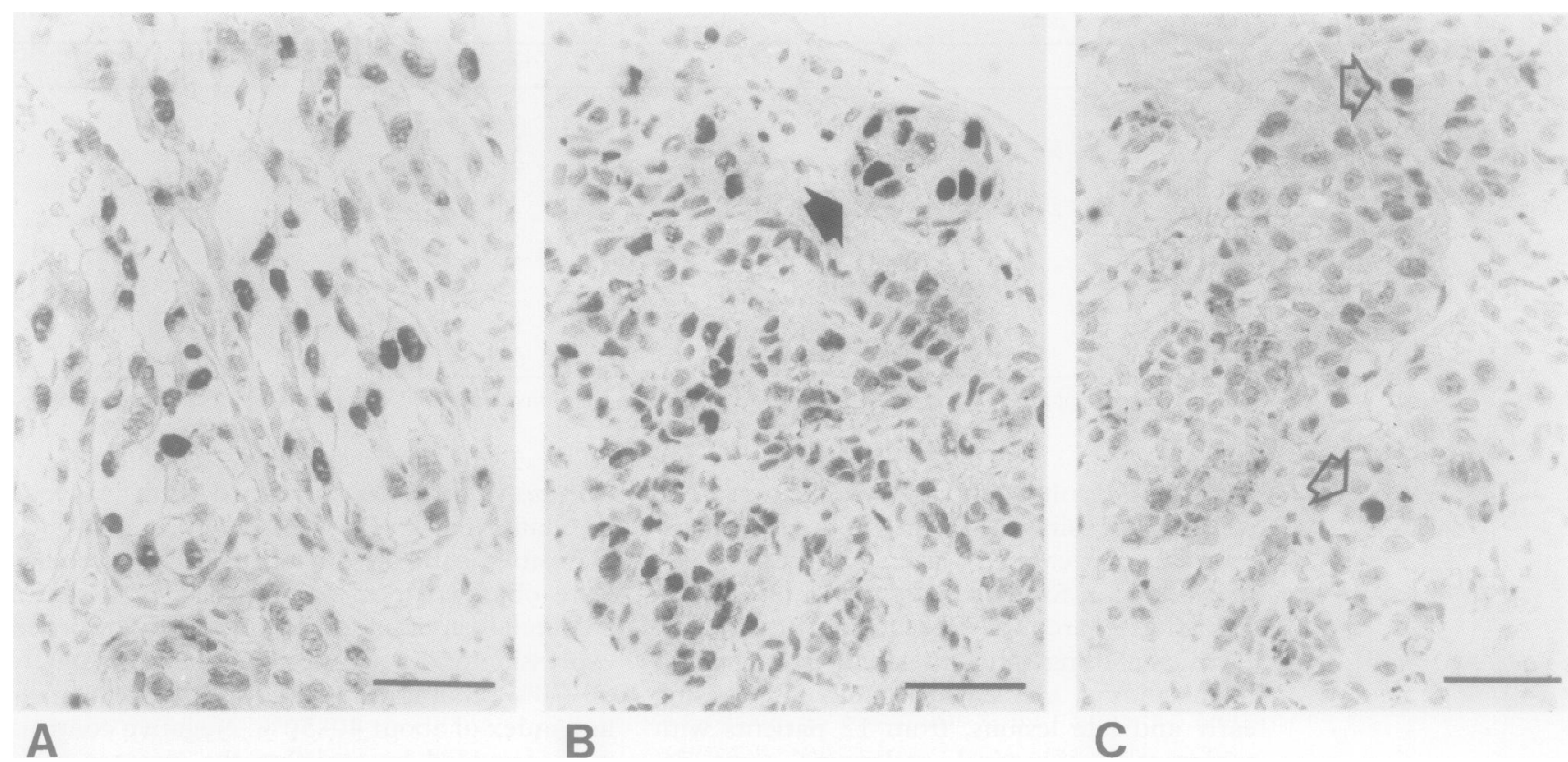

Figure 2 Recurrent conjunctival melanoma in patient 3 with PCNA immunoexpression in both the early $(A)$ and late $(B)$ lesions. Note the increased number of immunoreactive cells in the late lesion. The staining pattern is variable and some intensely stained cells can be seen (closed arrow). Some minimal and focal staining for the p53 gene product (open arrows) was present in both the early (not shown) and late (C) lesions. All sections were counterstained with Mayer's haematoxylin. Original magnification $\times 630$. Bar $=50 \mathrm{~mm}$.

and all completed the study. The median interval between early and late recurrences was 538 days (10th and 90th centiles, 227 and 1407 days, respectively).

\section{IMMUNOSTAINING}

A strong granular staining pattern was evident in the nuclei of the PCNA postive tumours. In PAM lesions these cells appeared singly (fig 1); however, in melanomas PCNA positive cells appeared as small clusters (figs $2 \mathrm{~A}$ and $2 \mathrm{~B}$ ). A large proportion of cells also displayed weaker immunoreactivity, particularly cells undergoing mitosis, possibly due to dissolution of the nuclear membrane. Although considerable intratumoural heterogeneity was a common feature, PC10 intra-nuclear immunoreactivity was present in all conjunctival melanomas.

Expression of p53 protein in melanomas was limited to small nodules or even single cells, which were surrounded by tumour cells without apparent immunoreactivity (fig 2C). However, the staining pattern of the small number of $\mathrm{p} 53$ positive cells was almost always strong and granular. The BP53-12-1 antibody showed a more distinct staining pattern than the DO7 or 1801 clones. In two conjunctival melanomas, only the BP53-12-1 antibody invoked a positive response. Staining with 3-amino-9ethylcarabazole produced a red colour that could be easily differentiated from melanin.

\section{REPRODUCIBILITY}

Repeated PC10 counts for early recurrent lesions indicated good intra-observer agreement between the two counts. The mean (SD) of the difference between the paired counts was $-4.8(16.5)$ and a graphical display (fig 3) suggested that the difference was independent of the average PC10 count. The two tailed $t$ test for paired data confirmed the absence of bias $(p=0.33)$. The $95 \%$ CI of the difference in counts was $-15 \cdot 3$ to $5 \cdot 7$.

\section{PRIMARY ACQUIRED MELANOSIS}

Of the nine specimens of atypical PAM that progressed to melanoma, seven contained PC10 positive melanocytic cells. The immunopositive cells often appeared in the middle or superficial part of the epithelium (fig 1). By contrast, only two specimens from patients who did not undergo subsequent malignant transformation contained a few $\mathrm{PC} 10$ positive cells in the basal layer. The remaining seven specimens in this group did not contain PC10

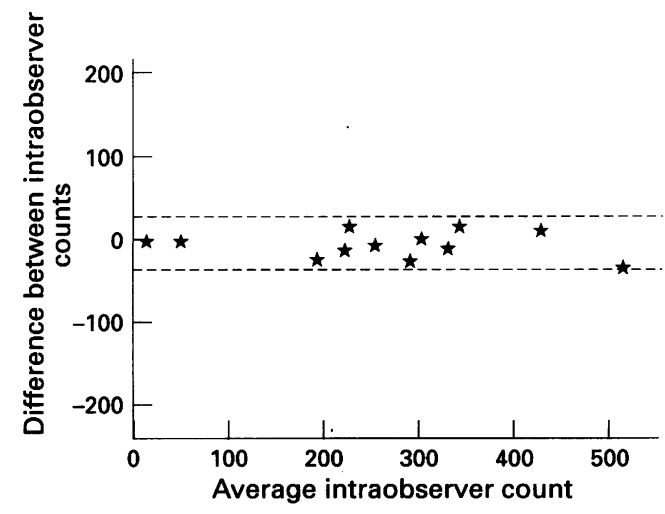

Figure 3 Assessment of reproducibility showing the difference between the repeated PC10 counts for each conjunctival melanoma (early lesions) plotted against the average of the two counts. The differences are small and seem to be independent of the average count. The broken lines indicate the $95 \%$ limit of agreement defined as the mean difference $\pm 2 S D$. 


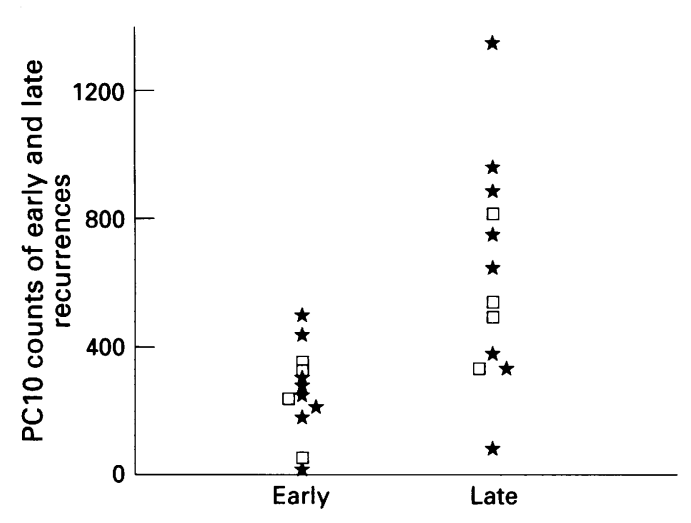

Figure $4 \quad P C 10$ counts for the early and late lesions of 12 patients with conjunctival melanoma. p53 immunopositive tumours are indicated by open boxes.

positive cells. This difference is statistically significant $(p=0.028)$, but the sample was too small for life table based analysis. There was no difference between the survival times of the two groups when the event of interest was defined as the development of invasive melanoma $(p=0.12)$. In contrast to PC10, none of the 18 PAM specimens contained $\mathrm{p} 53$ positive cells.

\section{CELL PROLIFERATION OVER TIME}

The PC10 counts for the two specimens of each conjunctival melanoma are presented in fig 4. The mean of the PC10 counts in early lesions was 260 , whereas the mean of the PC10 counts in late lesions was 632 . The mean (SD) of the differences between the PC10 counts of early and late lesions was 371 (342). A hypothesis test of the paired data indicated a significant increase in PC10 counts $(p=0.003)$, with a corresponding $95 \%$ CI of 154-588.

\section{P53 IMMUNOREACTIVITY}

In four cases the conjunctival melanoma specimens contained some degree of detectable p53 immunoreactivity. In the early lesions these counts were $15,25,36$, and 133 immunopositive cells per measured area as defined above. In the late lesions the comparative scores were $7,45,43$, and six cells. The fractions of p53 immunoreactive cells to PC10 immunopositive cells in the late lesions were $1.4 \%$, $1 \cdot 8 \%, 5 \cdot 5 \%$, and $7 \cdot 9 \%$, respectively. In the late lesions of the four cases with p53 positive conjunctival melanoma the mean (SD) PC10 count was 546 (199), whereas the eight patients with immunonegative tumours had a mean corresponding PC10 count of 675 (405). This difference was not significant $(p=0.57 ; t$ test for independent data; 95\% CI 357-615).

\section{Discussion}

Folberg et $a l^{4}$ demonstrated that $50 \%$ of atypical PAM give rise to melanoma, and that tumour progression was more common in the presence of epitheloid cells and in lesions with a predominant pattern other than basilar hyperplasia. Furthermore, these data suggest that the detection of proliferating melanocytes by staining with PC10 may be used to predict which lesions that are likely to undergo malignant transformation. In this study the median time interval between a confirmed diagnosis of atypical PAM and subsequent development of melanoma was three years; this interval was 2.5 years in a previous report. ${ }^{20}$ In the present study patients with atypical PAM who did not develop melanoma were followed for four years and it is unlikely that these patients will develop melanoma.

Most conjunctival melanomas with multiple recurrences ultimately require orbital exenteration, ${ }^{3}$ and may become more aggressive over time. As a high PC10 count in conjunctival melanomas correlates with an adverse prognosis, ${ }^{6}$ it is likely that the increase in PC10 counts over time in recurrent conjunctival melanoma reflects more aggressive behaviour. Four recurrences from two cases of conjunctival melanoma were available for study by immunohistochemistry. The limited data from these two tumours suggest that the PC10 count increases sharply at exenteration and while further studies are needed to elucidate the clinical importance of the increase in cell proliferation over time, PC10 counts may be used to monitor recurrent conjunctival melanoma. In the event of a significant increase in the proliferating cell count, aggressive therapy may have to be undertaken.

The epitope recognised by PC10 is stable for most fixation periods used for routine specimens. ${ }^{21}$ However, archival material may have been fixed for prolonged periods of time, which may result in a curtailed staining pattern. Recent data indicate that heating tissue sections in a microwave oven in an antigen retrieval solution containing heavy metal salts or distilled water results in consistent staining patterns in specimens fixed in formalin for up to 24 months. ${ }^{2223}$ These findings were confirmed by our pilot study, using fixation periods of up to 14 days. We found that citrate buffer produced staining as satisfactory and reproducible as that obtained using a commercially available antigen retrieval solution (Biogenex).

In this study p53 positive and negative conjunctival melanomas had similar PC10 counts. This is in agreement with a study by Barbareschi et $a l^{16}$ who found that p53 expression is not associated with the percentage of PC10 labelled cells in neoplasms of the central nervous system. However, studies on oesophageal carcinomas $^{24}$ and lung carcinomas ${ }^{17}$ suggest that in these tumours the p53 tumour suppressor gene may upregulate cell proliferation.

Data on the pattern of p53 expression in cutaneous malignant melanomas is limited and contradictory. Several studies indicate that many cutaneous melanomas, ${ }^{25-27}$ and melanoma cell lines ${ }^{28}$ exhibit p53 immunoreactivity. By contrast, an additional report only observed immunoreactivity in $5 \%$ of 61 cutaneous malignant melanomas. ${ }^{29}$ Recently, Platz et al failed to detect p53 expression in cutaneous dysplastic naevi and only recognised immunoreactivity in $17 \%$ of invasive cutaneous melanomas. ${ }^{29 \mathrm{~A}}$ 
These findings parallel those of the present study.

Tobal et $a l^{30}$ studied expression of p53 in freshly sampled ocular melanomas and found a positive staining pattern in 12 of 18 cases of choroidal melanoma. Exons 5 to 8 of the p53 gene of two of these melanomas were sequenced and point mutations were found at codons 238 and 253. A study of a family with the Li-Fraumeni syndrome also documented the presence of $\mathrm{p} 53$ immunoreactivity in two historical specimens of uveal melanoma. ${ }^{31}$ However, positive p53 immunostains should not be regarded as unequivocal evidence of p53 gene mutations. Although several studies have reported an excellent correlation between positive immunostains and missense mutations detected by DNA sequencing, ${ }^{3233}$ some authors reported missense mutations in the p 53 gene of tumours lacking p53 immunoreactivity. ${ }^{34}$ Others have been unable to detect mutations in cases with positive p53 immunostains. ${ }^{35}$

The findings presented here suggest that p53 alterations are not significant events in the tumorigenesis of conjunctival melanoma. Furthermore, if $\mathrm{p} 53$ mutation is indeed a significant event in the pathogenesis of conjunctival melanoma this would be expected to correlate with cell growth. ${ }^{36}$ The results of this study indicate that $\mathrm{p} 53$ positive conjunctival melanomas do not contain more proliferating cells than tumours completely lacking p53 immunoexpression.

In conclusion, examination of the expression of proliferating cells in atypical PAM may be used as an adjunct to predict which lesions will progress to melanoma. The increase in the number of proliferating cells over time in recurrent conjunctival melanomas probably reflects more aggressive behaviour and may be used to monitor recurrence. The absence of p53 expression in PAM and minimal staining of conjunctival melanomas did not correlate with cell growth, suggesting that alterations in the p53 tumour suppressor gene are uncommon and late events in conjunctival melanoma, and that p53 expression is unlikely to be a useful prognostic indicator.

This work was supported financially by the Karolinska Institute and the Carmen and Bertil Regnér Foundation. The author gratefully acknowledges the expert technical assistance of $M$ Berit Spangberg, Ms Margareta Oskarsson, and Ms Maud Leindahl.

1 Seregard S, Kock E. Conjunctival malignant melanoma in Sweden 1969-91. Acta Ophthalmol (Copenh) 1992;70: 289-96.

2 DePotter P, Shields CL, Shields JA, Menduke H. Clinical predictive factors for development of recurrence and metaf Ophthalmol 1993;77:624-30.

3 Paridaens ADA, McCartney ACE, Minassian DC, Hungerford $J$. Orbital exenteration in 95 cases of primary conjunctival malignant melanoma. Br $\mathcal{f}$ Ophthalmol 1994; 78:520-8.

4 Folberg R, McLean IW, Zimmerman LE. Primary acquired melanosis of the conjunctiva. Hum Pathol 1985;16:129-35.

5 Landberg G, Roos G. Antibodies to proliferating cell nuclear andigen $\mathrm{G}, \mathrm{Roos} \mathrm{G}$. Antibodies to proliferating cell nuclear
antigen as S-phase probes in flow cytometric analysis. antigen as S-phase probes
Cancer Res 1991;51:4570-4.

6 Seregard S. Cell proliferation as a prognostic indicator in conjunctival malignant melanoma. Am F Ophthalmol 1993; 116:93-7.

7 Levine AJ, Momand J. Tumor suppressor genes: the p53 and retinoblastoma sensitivity genes and gene products. Biochim Biophys Acta 1990;1032:119-36.

8 Baker SJ, Fearon ER, Nigro JM, Hamilton S, Preisinger $\mathrm{AC}$, Jessup JM, et al. Chromosome 17 deletions and p53 gene mutations in colorectal carcinomas. Science 1989; 244:217-21.

9 Nigro JM, Baker SJ, Preisinger AC. Mutations in the p53 gene occur in diverse human tumour types. Nature 1989 ; 342:705-8.

10 Hollstein M, Sidransky D, Vogelstein B, Harris CC. p53 Mutations in human cancers. Science 1991;253:49-53.

11 Levine AJ, Momand J, Finlay CA. The p53 tumour suppressor gene. Nature 1991;351:453-6.

12 Leong AS-Y, Milios J, Duncis CG. Antigen preservation in microwave irradiated tissues: a comparison with formaldehyde fixation. F Pathol 1988;156:275-82.

13 Shi S-R, Key ME, Kalra KL. Antigen retrieval in formalinfixed, paraffin-embedded tissues: an enhancement method for immunohistochemical staining based on microwave oven heating of tissue sections. $\mathcal{f}$ Histochem Cytochem 1991 ; 39:741-8.

14 Taylor CR, Shi S-R, Chaiwun B, Young L, Imam SA, Cote RJ. Strategies for improving the immunohistochemical staining of various intranuclear prognostic markers in formalin-paraffin sections: androgen receptor, estrogen formalin-paraffin sections: androgen receptor, estrogen receptor, progesterone receptor, $\mathrm{p} 53$ protein, proliferating
cell nuclear antigen and $\mathrm{Ki} 67$ antigen revealed by antigen cell nuclear antigen and Ki67 antigen revealed by an
retrieval techniques. Hum Pathol 1994;25:263-70.

15 Matias-Guiu X, Cuatrecasas M, Musulen E, Prat J. p53 expression in anaplastic carcinomas arising from thyroid papillary carcinomas. $\mathcal{f}$ Clin Pathol 1994;47:337-9.

16 Barbareschi M, Iuzzolini P, Pennella A, Allegraza A, Arrigoni G, Della Palma $P$, et al. $\mathrm{p} 53$ protein expression in central nervous system neoplasms. f Clin Pathol 1992;45:583-6.

17 Korkolopoulou P, Oates J, Crocker J, Edwards C. p53 expression in oat and non-oat small cell lung carcinomas: correlations with proliferating cell nuclear antigen. $f$ Clin Pathol 1993;46:1093-6.

18 Poller DN, Roberts EC, Bell JA, Elston CW, Blamey RW, Ellis IO. p53 Protein expression in mammary ductal carcinoma in situ: Relationship to immunohistochemical expression of estrogen receptor and c-erbB-2 protein. Hum Pathol 1993;24:463-8.

19 Wee A, Teh M, Raju GC. Clinical importance of $\mathrm{p} 53$ protein in gall bladder carcinoma and its precursor lesions. $\mathcal{f}$ Clin Pathol 1994;47:453-6.

20 Folberg R, McLean IW, Zimmerman LE. Conjunctival melanoma and melanosis. Ophthalmology 1984;91:673-8.

21 Wolf H, Dittrich KL. Detection of proliferating cell nuclear antigen in diagnostic histopathology. F Histochem Cytochem antigen in diagnos

22 Greenwell A, Foley JF, Maronpot RR. An enhancing method for immunohistochemical staining of proliferating cell nuclear antigen in archival rodent tissues. Cancer Lett 1991 59:251-6.

23 Haerslev T, Jacobsen GK. Microwave processing for immunohistochemical demonstration of proliferating cell nuclear antigen (PCNA) in formalin-fixed and paraffinembedded tissue. APMIS 1994;102:395-400.

24 Sasano H, Miyazaki S, Gooukon Y, Nishihira T, Sawai T, Nagura H. Expression of p53 in human esophageal carcinoma: An immunohistochemical study with correlation to proliferating cell nuclear antigen expression. Hum Pathol 1992;23:1238-43.

25 Stretch JR, Gatter KC, Ralfkiaer E, Lane DP, Harris AL Expression of mutant p53 in melanoma. Cancer Res 1991; 1:5976-9.

26 Akslen LA, Morkve O. Expression of p53 protein in cutaneous melanoma. Int f Cancer 1992;52:13-16.

27 McGregor JM, Yu CC-W, Dublin EA, Barnes DM, Levison DA, MacDonald DM. p53 immunoreactivity in human malignant melanoma and dysplastic naevi. $\mathrm{Br} \mathcal{F}$ Dermato 1993;128:606-11.

28 Weiss J, Schwechheimer K, Cavenee WK, Herlyn M, Arden KC. Mutation and expression of the 533 gene in malignan melanoma cell lines. Int $\mathcal{f}$ Cancer 1993;54:693-9.

29 Lassam NJ, From L, Kahn HJ. Overexpression of p53 is a late event in the development of malignant melanoma. Cancer Res 1993;53:2235-8.

29A Platz A, Ringborg U, Grafström E, Höög A, Lagerlöf B. Immunohistochemical analysis of the N-ras p21 and the p53 proteins in naevi, primary tumours and metastases of p53 proteins in naevi, primary tumours and metastases of
human cutaneous malignant melanoma: increase imhuman cutaneous malignant melanoma: increase immunopositivity

30 Tobal K, Warren W, Cooper CS, McCartney A, Hungerford J, Lightman S. Increased expression and mutation of p53 in choroidal melanoma. Br $\mathcal{F}$ Cancer 1992;66:900-4.

31 Jay $\mathbf{M}$, McCartney ACE. Familial malignant melanoma of the uvea and p53: A Victorian detective story. Surv Ophthalmol 1993;37:457-62.

32 Esrig D, Spruck CH III, Nichols PW, Chaiwun B, Steven $\mathrm{K}$, Groshen S, et al. p53 Nuclear protein accumulation correlates with mutations in the p 53 gene, tumor grade, and stage in bladder cancer. Am f Pathol 1993;143:1389and

33 Cordon-Cardo C, Dalbagni G, Saez GT, Oliva MR, Zhang Z-F, Rosai J, et al. p53 Mutations in human bladder cancer: Genotypic versus phenotypic patterns. Int 7 Cancer cancer: Genotypic

34 Scarpa A, Capelli P, Mukai K, Zamboni G, Oda T, Iacono C, et al. Pancreatic adenocarcinomas frequently show p 53 gene mutations. Am $\mathcal{F}$ Pathol 1993;142:1534-43.

35 Kennedy SM, MacGeogh C, Jaffe R, Spurr NK. Overexpression of the oncoprotein p53 in primary hepatic tumors of childhood does not correlate with gene mutations. Hum Pathol 1994;25:438-42.

36 Vogelstein B. A deadly inheritance. Nature 1990;348:681-2. 